\title{
The simple calibration procedure on the example of small town water supply system
}

\author{
Jarosław Sowiński ${ }^{1, *}$, Adam Hofman ${ }^{1}$, and Marek Dziubiński ${ }^{1}$ \\ ${ }^{1}$ Faculty of Process and Environmental Engineering, Lodz University of Technology (TUL), 90-924 \\ Lodz, Wolczanska 213 str., Poland
}

\begin{abstract}
The practical application of the model of water supply network realized in the program Epanet 2 requires the calibration of the model. The proposed simple calibration procedure, allows for taking into account the changes in resistance caused by the aging process, to be substituted by resistance coefficient $\mathrm{K}$. In order to determine the substitute resistance coefficient $\mathrm{K}$, the fire hydrant flow tests could be used, which allows to determine the aging for a given material. Calibration of the water supply network model is shown on the example of a small urban network in central Poland..
\end{abstract}

\section{Introduction}

The constructing of the model of the water supply system is a multi-step, hierarchical process including the identification and mapping of the structure of the water supply system, the determination of hydraulic parameters of each network pipeline and mapping the distribution of water consumption in each area of water supply system including the parameters of the water supply. At every stage of the construction of the model, the results of these actions have a significant impact on its adequacy and consequently on the usefulness of the research work on the water supply network.

To obtain the satisfying results, it is required the statistical data of both: the production and the consumption of water over the years as well as technical-technological data of water supply network $[1,2]$.

In the course of operating, iron and steel pipelines built in the past including those which contained bitumen coating on the inner side underwent incrustations due to fouling transported with the water or the product of corrosion of the pipe material (chemical residues and hydrobiological sediment - biofilm). As a result, the roughness of the internal walls of the pipelines increases and at the same time, reduces the active cross sectional area of the pipe. Changing of the hydraulic resistance, or in other words, the decrease rate of hydraulic efficiency of the individual sections of the network, can lead to changes in the hydraulic parameters of the water supply. Moreover, changes in the, residential, commercial and industrial building can significantly affect the proper distribution of water in the water supply system and thus, it also involves the need to increase the amount of discharge pumps, the substitute or periodic cleanings of the pipes or the construction of

\footnotetext{
*Corresponding author: jaroslaw.sowinski@p.lodz.pl
} 
additional pipelines $[3,4]$ The process of fitting the model of water supply network to the actual conditions that prevail in the water supply network is called calibration $[5,6,7]$ presented the general state of knowledge concerning the calibration of water supply networks. The apparent success of the application of automated calibration procedures led to the development of a number of commercial software, for example Epanet Calibrator [8].

The main aim of this work is to propose a simple calibration procedure of the water supply system on the example of a small urban network. The methodology is based on data obtained from the fire hydrant flow tests and it uses them to determine the value of substitute resistance of the pipelines, taking into account the change in hydraulic resistance resulting from the process of aging or malfunction of the fittings.

\section{Methods}

The presented solutions and assumptions can lead to satisfying results in the calibration of the network in a fairly simple way. There are several advantages of this solution. Firstly, low demand for data input. Secondly, it allows us to identify the sections of the network with altered resistance.

The values of following parameter: pressure, volumetric flow rate, roughness of the pipelines, pipes diameter, the daily and seasonal variation of water demand should be determined through the calculation process called calibration. A simplified method of calibration of the water supply system is based on the use of the fire hydrant flow tests on the characterization of network aging with a single, substitute resistance coefficient $K$. This coefficient is taken into account in the program Epanet 2 [9] while defining a pipeline of the water supply network. The proposed solution enabling calibration of the water supply system takes into account the assignment of so designated substitute resistance coefficient $K$ to a pipeline made from a given material, and searching for its unit value. The idea of defining the substitute resistance coefficient $K$ is closely associated with the appointment of substitute resistance using equations (1) and (2):

where:

$$
\Delta h=\lambda \frac{L U^{2}}{2 D g}+\xi \frac{U^{2}}{2 g}
$$

$$
\begin{aligned}
& \Delta h \text { - pressure drop }\left[\mathrm{m} \mathrm{H}_{2} \mathrm{O}\right] \\
& \lambda \text { - Darcy friction factor [-] } \\
& L \text { - pipeline length }[\mathrm{m}] \\
& U \text { - mean water velocity }[\mathrm{m} / \mathrm{s}] \\
& D \text { - pipeline diameter }[\mathrm{m}] \\
& g \text { - acceleration of gravity }\left[\mathrm{m} / \mathrm{s}^{2}\right] \\
& \xi \text { - substitute resistance coefficient [-] }
\end{aligned}
$$

The fiction factor can be determined on the basis of Colebrooke - White equation:

where:

$$
\frac{1}{\sqrt{\lambda}}=2 \log _{10}\left(\frac{k}{3.7}+\frac{2.51}{\operatorname{Re} \sqrt{\lambda}}\right)
$$

$$
\begin{aligned}
& \lambda \text { - Darcy friction factor [-] } \\
& k \text { - relative roughness [-] } \\
& \operatorname{Re} \quad-\text { Reynolds number [-] }
\end{aligned}
$$

The equation describing relative roughness $k$ :

where:

$$
k=\frac{\varepsilon}{D}
$$

$\varepsilon$ - absolute roughness of new pipelines [mm]

$D$ - pipeline diameter $[\mathrm{mm}]$ 
After simple transformation, the equitation (1) looks as follows:

$$
\xi=\frac{2 \Delta h g}{U^{2}}-\lambda \frac{L}{D}
$$

Values of unitary substitute resistance coefficient $K_{L}$ for groups of pipelines made of a particular materials is calculated from the relationship:

where:

$$
K_{L}=\frac{\xi}{L}
$$

$\xi$ - substitute resistance coefficient [-]

$L$ - pipeline length $[\mathrm{m}]$

The unitary substitute resistance coefficient $K_{L}$ determined in this way is transferred to the network model made in the Epanet 2 in the place of the loss coefficient for the respective pipeline made of a given material. The rest of the calibration of the water supply system requires the assumption that the aging of the network for pipelines made of the same material is constant. The process of the identification of individual pressure drops in the sections of pipes of water supply network is based on iterative matching of hypothetical changes occurring due to aging of the pipelines which causes the pressure drops in comparison with the pressure values obtained during the field research. Matching takes place on the basis of pressure measurements obtained during the fire hydrant flow tests. It is also assumed that the pressure drop occurring in the pipeline during normal water demand will be negligible in comparison with the losses caused by the increased flow of water in pipes during hydrant fire flow demand. Opening of the fire hydrant causes the significant increase in the water flow, which in turn increases the rate of water flow and consequently the pressure drop.

The calculations, according to the assumptions, were made for the model of water supply network Poddębice. The results of the calculations for the exemplary pipeline constructed of asbestos-cement (AC) which has a diameter of $100 \mathrm{~mm}$ and absolute roughness $\varepsilon=0.6 \mathrm{~mm}$ (according to the data in manufacturer's catalog) are as follow: the pressure drop due to typical water consumption $(0.32 \mathrm{l} / \mathrm{s})$ is below level of sensitivity instrument $\left(0.02 \mathrm{mH}_{2} \mathrm{O}\right)$, but pressure drop due to fire hydrant flow test $(8.56 \mathrm{l} / \mathrm{s})$ is greatly higher $\left(9.95 \mathrm{mH}_{2} \mathrm{O}\right)$. The analysis of data, shows that during a typical water consumption the pressure drops are much smaller than those caused by the hydraulic vent. Therefore, for small water supply systems as well as for areas with low water flow, pressure drops caused by the typical daily water consumption can be omitted. In practice, it could be assumed that the pressure measured before the fire hydrant flow tests as the static pressure.

\section{Results and Discussion}

Based on the above-mentioned assumptions, the calibration of the water supply network in the city Poddębice was performed. The water supply system of the city Poddębice fulfill the water needs for more than 8000 residents of the town and surrounding areas, amounting to an average of $1200 \mathrm{~m}^{3} / \mathrm{d}$. The water in the city is distributed through a network of water supply pipelines with a total length of about $35 \mathrm{~km}$. The water supply can be classified as a mixed network.

On the basis of data obtained from the Municipal Water and Sewage Company. Ltd. in Poddębice, which deals with the operation of the water supply network in the Municipality and the city of Poddębice it may be concluded that the most abundant material from which the water supply system is constructed is a cast iron (CI) - $16 \mathrm{~km}$ long, followed by plastics (HDPE/PVC) - $15 \mathrm{~km}$ long and asbestos cement (AC) $4 \mathrm{~km}$ long.

The model of the water supply system was developed in a computer program Epanet 2 [5]. All pipelines of transit network were included during the process of 
schematization. The values of water division on a given node were established on the basis of the average annual consumption of registered water consumers. As a result, each network node can be assigned a value indicating its share of total water consumption. Technical and technological data enables us to specify the length and diameter of water pipes, as well as the pressure in the Water Treatment Plant (WTP) in water supply network Poddębice. On this basis, the record of the pressure in the WTP was established.

The measurements of pressure for selected hydrants in the water supply network Poddębice were conducted. The network is shown in Figure 1b, the dots indicate examined hydrants (57 hydrants in total during two years experiment), while rectangle mark the selected area of water supply network - see Figure 1a.

a)

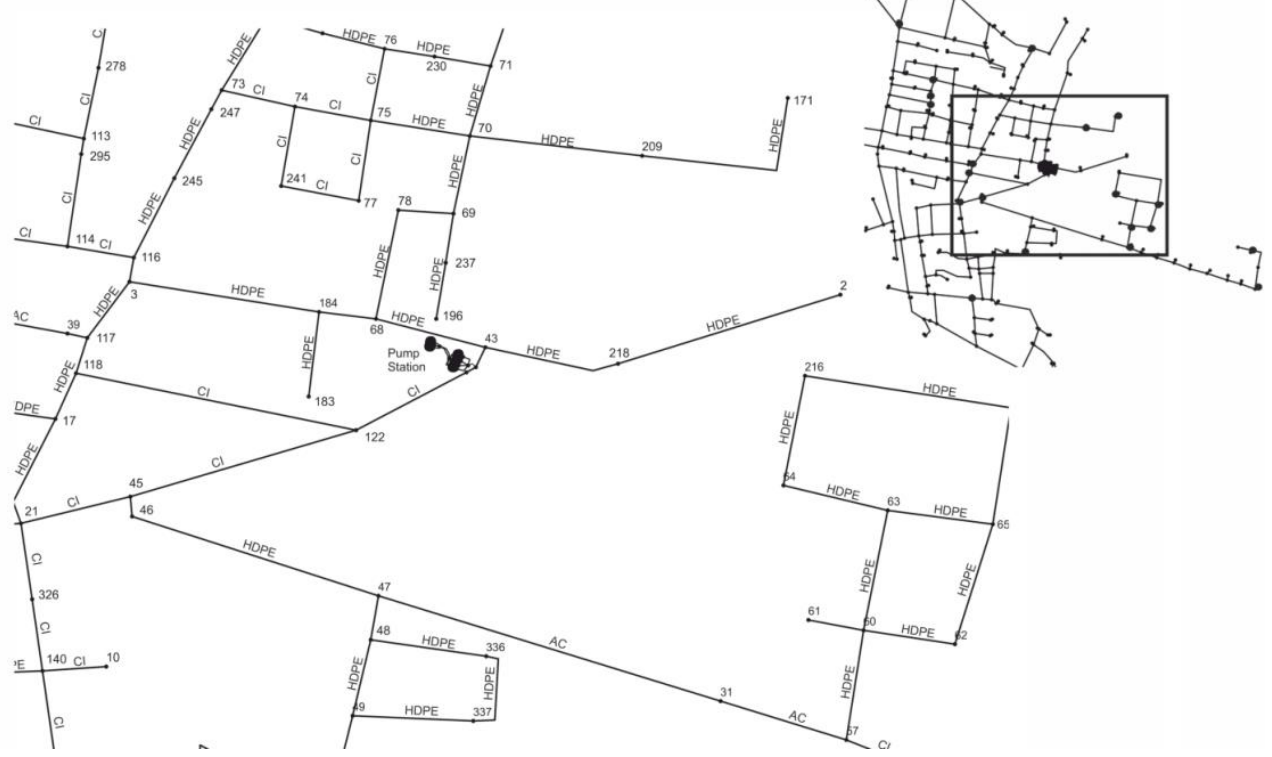

Fig. 1. The selected portion of the water supply network Poddębice, pipe material: plastic - HDPE; asbestos cement - AC; cast iron - CI (a); scheme of the water supply system Poddębice with the marked locations of the hydrant fire flow demand (b).

The pressure (static and dynamic) and the flow rate of water during the fire hydrant flow tests for selected fire hydrants were measured during the study. The study was conducted in two periods - October and May. The analysis of the results presents significant differences between static and dynamic pressure during the fire hydrant flow tests. Pressure drops can be caused by both the hydrant (damaged or leaking) and/or changes due to aging and damaged fittings. The calculation of the pressure (static and dynamic) and the comparison with the obtained results, were based on the model of the water supply network in Poddębice built in Epanet 2 and the catalogue values of roughness and diameter of pipelines. The achieved calculations are shown in Figure 2. 


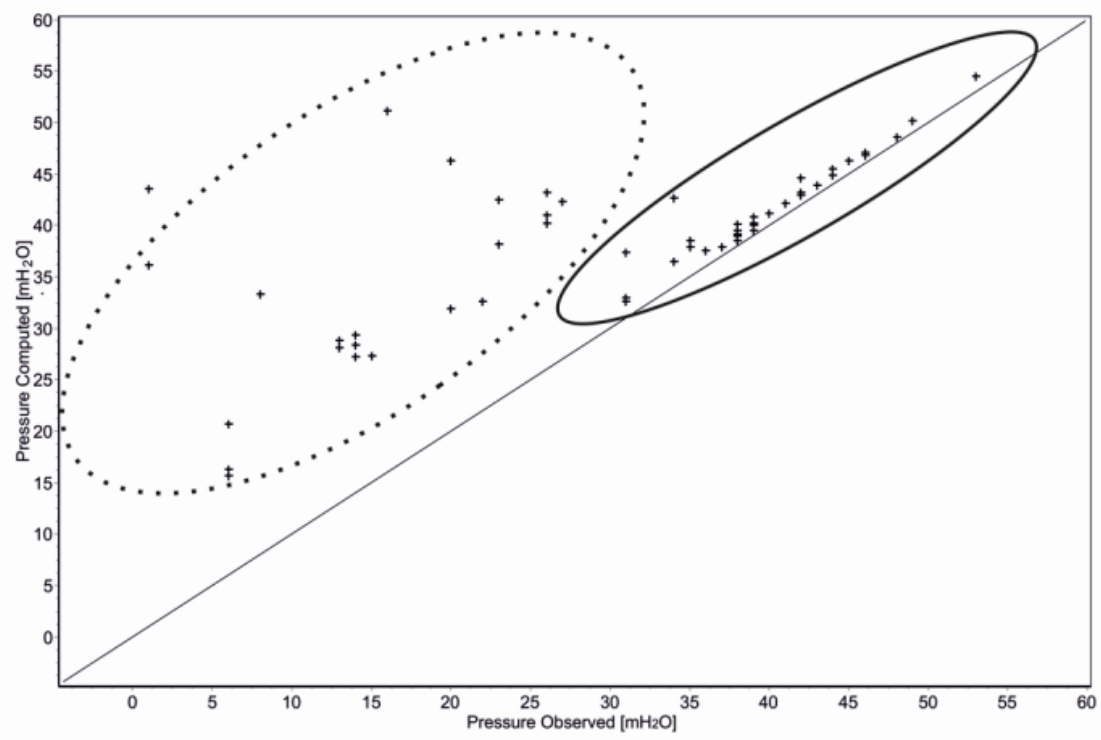

Fig. 2. Comparative results of calculated and experimental pressures before the calibration process.

Figure 2 presents the idea and the necessity for the calibration process. Points illustrating the static pressure (the figure marked with an oval black) show that there is almost no difference between the measured values with the values calculated in Epanet 2. This confirms the validity of the assumptions and the correct determination of measuring points on the ordinate. Analyzing the dynamic pressures (the figure marked with an dotted oval) prove that there are significant differences between observed and calculated values. It means that the calibration of the water supply system is required to achieve the correct network model. The coefficient of determination of calculated and experimental results equals 0.69 .

\section{The first approximation}

In order to determine experimental values of pressure drop for cast iron and asbestos cement pipelines two representative sections of such pipelines were selected. Selection of representative pipeline section was made by analyzing the pressure values obtained during the fire hydrant flow test. Pressure gauges were installed at the beginning and at the end of each part. It gives us the possibility to determine the value of the resistance coefficient for cast iron and asbestos cement pipes. Taking field measurements data into account, the values of the substitute resistance coefficients $\xi$ and $\mathrm{K}_{\mathrm{L}}$ were determined. For HDPE pipeline the unitary substitute resistance coefficient were equal $\mathrm{K}_{\mathrm{L}}=0$, for cast iron pipelines $\mathrm{K}_{\mathrm{L}}=5.9$ and for asbestos cement pipelines $\mathrm{K}_{\mathrm{L}}=0.6$. The third section of the measurement was used to determine the resistance coefficient for hydrant substitute resistance coefficient $K_{H}=10$.

The same values of the unitary substitute resistance coefficient $K_{L}$ determined on the basis of the measurements points (pressure drops for pipes made of various materials) were adopted for the entire network made of a given material. Simulation of model of water supply network for such specified parameters were performed. The coefficient of determination of calculated and experimental results equals 0.71 . The values of calculated pressures are adequate for the dynamic pressures in case of such specific unit values of unitary substitute resistance coefficient $K_{L}$ for individual materials and for most of the test points. However, there are places where calculated values of pressures differ significantly 
from the measured values when the unitary substitute resistance coefficient $K_{L}$ is determined - areas where water flows mainly through the pipes made of plastic. Thus, it is not possible to classify the divergence of the results as the impact of a fire hydrant. Moreover, it was noted that such defined resistance in the cast iron pipes is overestimated. Therefore, the iron pipelines were analyzed separately only in the part of the network (nodes: 21-45, 45-122 and 122-118; see Figure 1a). For the second approximation changes in plastics pipes are taken into account.

\section{The second approximation}

In the second approximation, the unitary substitute resistance coefficient $K_{L}$ for the cast iron out of the selected part of the network the calibration process of water supply system had to be re-determined. It was required to determine the resistance occurring in the network sections constructed of plastic. The determination of unitary substitute resistance coefficient $K_{L}$ values for the cast iron and plastic are: for HDPE pipeline the unitary substitute resistance coefficient were assumed $K_{L}=0.2$, for cast iron pipelines $K_{L}=0.12$ and for asbestos cement pipelines $K_{L}=0.6$. The coefficient of determination of calculated and experimental results equals 0.73 . With these specified values of unitary substitute resistance coefficient $K_{L}$, there are differences between the observed and calculated values. The most diverse values of pressures were observed during the flow in asbestos cement pipes and therefore, the adopted values of the unitary substitute resistance coefficient $K_{L}$ for the pipelines should be corrected. In addition, we observed a significant variation in the resistance of particular hydrants. This can be caused by possible damaging and/or aging of the fittings. This may be explained on the basis of a chart comparing the changes of predicted and calculated pressures in the sample hydrant (node 33) - Figure 3.

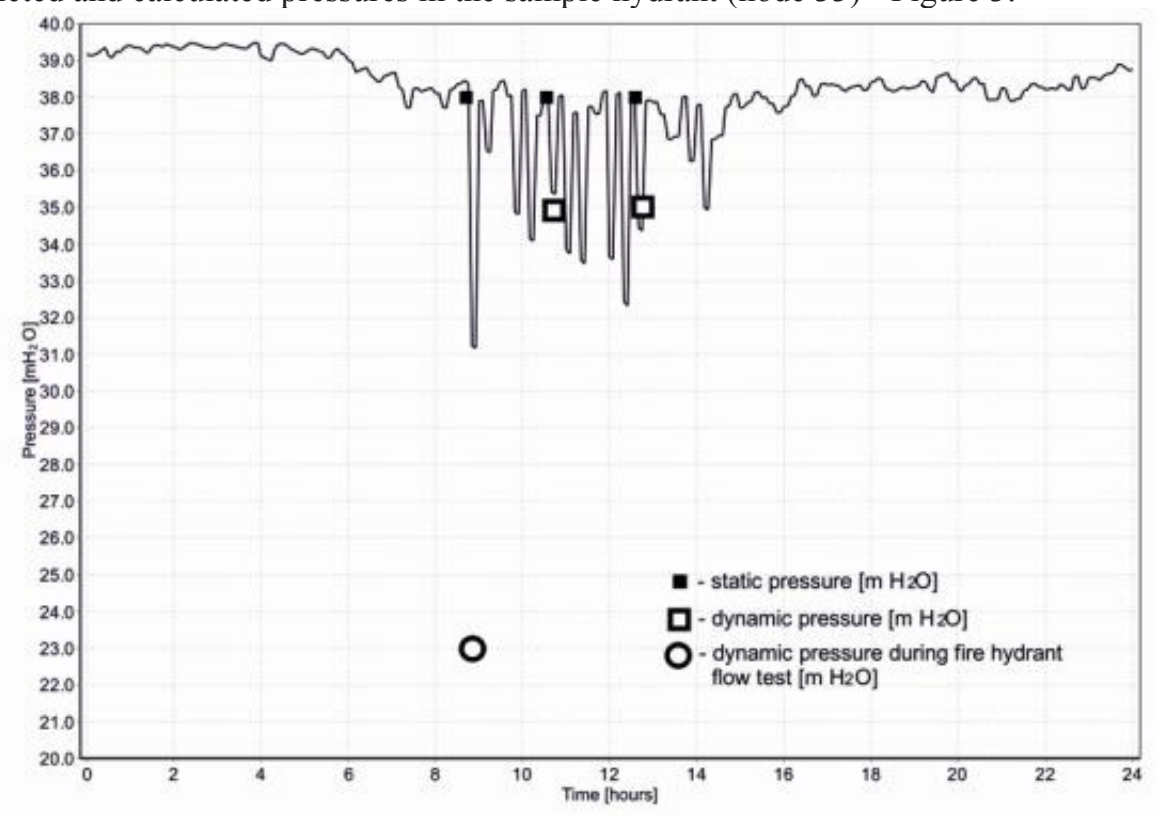

Fig. 3. Comparison of measured and calculated pressures for hydrant 45.

Figure 3 shows three series of measurements of static and dynamic pressures carried out on hydrant (node 45). The first measurement was carried out more or less at 9 am and it concerned measurements during the fire hydrant flow test, the other two series are the result of flows in other hydrants. We observe a significant discrepancy between the calculated and measured value of the dynamic pressure only for the first series. This indicates the 
underestimation of substitute resistance values $K_{H}$ for the hydrant. Therefore, in the third approximation we must also take the value of the substitute resistance coefficient $K_{H}$ for the individual hydrants into account.

Third approximation

During the third approximations of the calibration, it was required to redefine the substitute resistance coefficient for asbestos-cement pipes and for the individual hydrants $K_{H}$. For HDPE pipeline the unitary substitute resistance coefficient were assumed $K_{L}=0.2$, for cast iron pipelines $K_{L}=5.9$ (for nodes: $21-45-122-118$ ), for rest cast iron pipelines $K_{L}=0.3$ and for asbestos cement pipelines $K_{L}=0.2$. The unitary substitute resistance coefficient $K_{H}$ was in range between 30-100 for specific hydrants. The coefficient of determination of calculated and experimental results equals 0.99 . There is a visible variation of the values of substitute resistance coefficient $K_{H}$ for particular hydrants, which may reflect aging and/or damage of these hydrants.

The application of the presented methodology, is associated with certain simplifications. However, it was confirmed that the proposed solution makes it possible to calibrate the network in a fairly simple way.

\subsection{The procedure for calibration of the water supply network}

Based on the assumptions and the analysis of the described model, it was proposed the following calibration procedure:

1. The construction of the water supply network model in the computer program Epanet 2 based on the data, such as diameter and roughness of the pipelines, the division of water for each node and the output pressure of Water Treatment Plant (WTP).

2. The measurement of changes in pressure drops and water flow rate while the fire hydrant flow tests.

3. The measurement of pressure drop in representative sections of the network.

4. The determination of the unitary substitute resistance coefficient $K_{L}$ for representative sections of the network.

5. The implementation of the first approximation of the water supply system calibration, assuming equal values of the unitary substitute resistance coefficients $K_{L}$ for each material group and equal resistance values for all hydrants.

6. The change of the representative sections of the network and re-measurement of the pressure drops.

7. The implementation of the second approximation of the calibration of the supply system model and the correction of the unitary substitute resistance coefficient $K_{L}$ for pipelines based on the re-measurement of pressure drops.

8. The implementation of the second approximation of the calibration of the supply system model and the correction of the unitary substitute resistance coefficients $K_{L}$ for pipelines together with different substitute resistance coefficients $K_{H}$ values for the hydrants.

The proposed procedure allows in a relatively simple way for simplified calibration of small water supply models on the basis of data from the fire hydrant flow tests. 


\section{Conclusions}

The proposed calibration procedure is based on numerous field studies as well as a preparation before building a model of the water supply network. The calibration is affected by almost all technical and technological data. The substitute of changes in the network caused by aging of pipes with unitary substitute resistance coefficient $K_{L}$, allows for a relatively accurate, reliable and simple description of the processes occurring in the network. It seems to be rather impossible to determine the most important parameter (changes in roughness, narrowing of pipes diameter caused by sedimentation of particles or mechanical damage such as damaged equipment) without interfering with the structure of the water supply system. Additional difficulties, such as the impact of a hydrant on the values of received pressure drops can complicate the already very complex process.

The exemplary calibration of the real water supply network on the example of the small urban network seems to be appropriate for the intended purpose. This method allows to locate the defective or damaged sections of the network and hydrants what is one of the objectives of the calibration process.

The calibrated model of water supply network can be used to analyze the water supply network while simulating various scenarios of activities, such as hydraulic fire flow tests, the increased demand for water, expansion of water supply network and combining individual sections in rings.

The model of water supply network calibrated in this way enables rational planning and decision-making on the basis of information obtained from the analysis of the results of water supply network functioning. However, the periodic re-calibration of the model of water supply network is required due to the continuous and ongoing process of aging.

\section{References}

1. G. Sanz, R. Perez, Procedia Eng.70, 1495 (2014)

2. T. Koppel, A. Vasiljev, Adv. Eng. Soft., 40, 659 (2009)

3. T. M. Walski, Journal AWWA, 92 (1), 94 (2000)

4. T. M. Walski, N. Defrank, T. Voglino, R. Wood, E. Whitman, Proceedings of WDSA, Cincinnati, Ohio, USA, CD-Rom (2006)

5. D. Savic, Z. Kapelan, P. Jonkergouw, Urb. Water J, 6, 3 (2009)

6. Z. S. Kapelan, D. A. Savic, G. A. Walters,., EWRSA Symp., CD-Rom. (2002)

7. Z. S. Kapelan, D. A. Savic, G., A. Walters,. J. Hyd. Eng, 133 (8), 927 (2007)

8. N. Abe, P. B. Cheung, Epanet Calibrator (2008)

9. L. A. Rossman, EPANET 2 user manual. Washington DC (2000) 